\title{
¿Responden los micromoluscos a los cambios ambientales durante el Holoceno tardío en el sur del mar Caribe colombiano?
}

\author{
Ospina-Hoyos JB ${ }^{\bowtie}$, Palacio-Baena JA, Vásquez-Bedoya LF
}

\section{¿Micromollusc response to the late Holocene environmental changes in the southern Caribbean sea colombia?}

\begin{abstract}
Holocene environmental changes in the southern Caribbean Sea and their implications on the composition of marine micro and malacofauna are unknown. We embarked an oceanographic expedition aboard the ship, ARCQuindío of the Colombian Navy, to drill at three sites in the Gulf of Urabá using a platform gravity corer. To find possible correlations with paleoenvironmental changes during the late Holocene in the Gulf, we assessed the taxonomic composition (organic matter and calcium carbonate) and micromollusc abundance. The elevated richness and abundance of micromolluscs yields more calcium carbonate and less organic matter and answers to environmental changes in the late Holocene. We were able to define two contrasting environments in the Gulf of Urabá during the last 2800 years; an earlier environment dominated by marine waters and a more recent environment of a mixture of waters dominated by estuarine waters.
\end{abstract}

Keywords: Marine micromolluscs; late Holocene; Gulf of Urabá; calcium carbonate; organic matter.

Edited by Alberto Acosta四

Corporación Académica Ambiental y Grupo de Investigación en Gestión y Modelación Ambiental -GAIA- Facultad de Ingeniería. Universidad de Antioquia.

Received: 24-02-2014 Accepted: 30-04-2014

Published on line: 27-05-2014

Citation: Ospina-Hoyos JB, Palacio-Baena JA, Vásquez-Bedoya LF (2014) ¿Responden los micromoluscos a los cambios ambientales durante el Holoceno tardío en el sur del mar Caribe colombiano?. Universitas Scientiarum 19(3): 233-246 doi: 10.11144/Javeriana.SC19-3.rmca

Funding: Colciencias

Electronic supplementary material: N/A

\section{Introducción}

El golfo de Urabá es un estuario situado en el sur del mar Caribe colombiano y posee ambientes variables y frágiles, dinámicas oceanográficas intensas, efectos de diapirismo y volcanismo de lodos, altas tasas de erosión litoral, probables emergencias o subsidencias costeras y deterioro ambiental como resultado de la agroindustria y una cultura extractiva inmediatista. Las características oceanográficas del golfo están afectadas fundamentalmente por el aporte del sistema fluvial caudaloso del río Atrato, por las corrientes superficiales del Caribe y del Darién y por el régimen mareal irregular (Chevillot et al. 1993). 
Las dinámicas oceanográficas e hidrológicas del golfo, hacen que presente cambios importantes en el tiempo y diferencias espaciales en las condiciones ambientales predominantes. En estas circunstancias, los organismos de baja movilidad como los moluscos pueden indicar procesos dominantes a través del tiempo.

Los moluscos han sido estables en términos evolutivos y existen numerosas especies recientes, lo que significa una gran ventaja en investigaciones paleoambientales en comparación con otros microfósiles (Seilacher \& Hagadorn 2010). La abundancia y distribución de algunas especies de micromoluscos holocénicos tienen un gran significado paleobiológico y paleoambiental en áreas marinas y costeras (Farinati 1994, De Francesco 2002, Farinati et al. 2006), debido a que indican condiciones ambientales predominantes, entre otras respecto a la salinidad y los procesos de acumulación de sedimentos.

El estudio de la malacofauna reciente del golfo de Urabá la inició Manjarrés (1978) citado por (Werding \& Manjarrés 1978), quien reportó un total de 41 especies de la costa noreste. Palacio (1988) citó los gastrópodos Nerita virginea y Littorina nebulosa como parte de la fauna asociada a las raíces de Rbizophora mangle en la Bahía de Marririo. Otros estudios han contribuido al conocimiento de los moluscos del golfo (Díaz \& Puyana 1994, Valencia \& Díaz 2000, García \& Correa 2006, Gaviria 2006, Ospina 2008, Vargas 2008). Recientemente Palacio et al. (2014) realizaron una revisión que permitió consolidar un listado de 213 especies para el golfo.

En la actualidad se desconocen estudios sobre la malacofauna subfósil en el golfo de Urabá, área del Caribe colombiano donde confluyen masas de aguas marinas y limnéticas. Por lo tanto, se estudiaron los micromoluscos en núcleos de sedimentos, así como la materia orgánica y el carbonato de calcio para conocer los cambios ambientales durante el Holoceno tardío en el golfo, una región en donde se desconocen las condiciones paleoambientales predominantes durante este tiempo.

Descripción del área de estudio: El golfo de Urabá está localizado en el área austral del mar Caribe (Figura 1), tiene un área de $4291 \mathrm{Km}^{2}$ y se extiende desde Punta Arenas al norte de la costa oriental hasta cabo Tiburón en la costa occidental $\left(7^{\circ} 54^{\prime} \mathrm{N}, 8^{\circ} 40^{\prime} \mathrm{N}\right.$ y

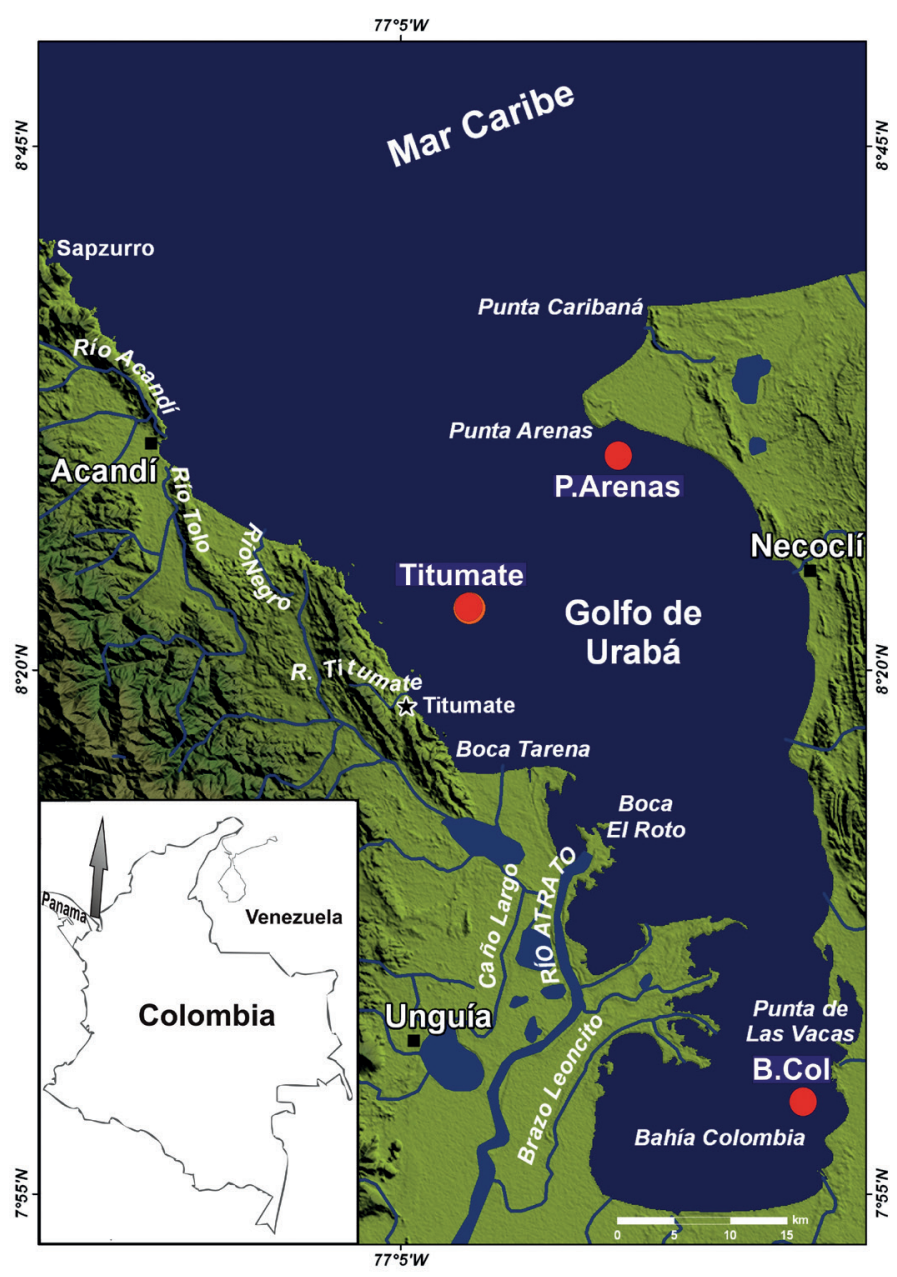

Fig. 1. Área de estudio y localización de los núcleos de sedimentos en las estaciones Titumate, Punta Arenas (P. Arenas) y Bahía Colombia (B. Col) en el golfo de Urabá.

$76^{\circ} 56^{\prime} \mathrm{W}, 7^{\circ} 23^{\prime} \mathrm{W}$; Chevillot et al. 1993). El golfo es la mayor entrada del mar Caribe en tierra colombiana, presenta una forma de U alargada de más de $100 \mathrm{~km}$, con un eje de orientación norte-sur a noreste-sureste. La profundidad en la entrada y a lo largo del eje central del golfo no supera los $65 \mathrm{~m}$ y en la Bahía, Colombia alcanza $30 \mathrm{~m}$ (Chevillot et al. 1993).

El golfo se encuentra en una región de circulación ecuatorialmarítimainfluenciada duranteel año de forma alterna por el mar Caribe y los aportes de los tributarios, principalmente los ríos Atrato y León (Lozano 1998). La circulación general está relacionada con la posición de la Zona de Convergencia Intertropical (ZCIT), una franja de baja presión en la que convergen los vientos 
alisios del noreste y el sureste y cuyo comportamiento obedece a los cambios estacionales en las temperaturas superficiales oceánicas (Philander et al. 1996, Mesa et al. 1997). La precipitación anual alcanza cerca de $2.500 \mathrm{~mm} /$ año (IGAC 2008) y adicionalmente el río Atrato drena un caudal de $4.500 \mathrm{~m}^{3}$. s-1 (Zamora et al. 2008), el cual aporta gran parte de agua dulce del Chocó biogeográfico, considerada una de las zonas más lluviosas del mundo (IGAC 2008).

\section{Materiales y métodos}

Trabajo de campo: En diciembre de 2009, se realizó una campaña oceanográfica a bordo del buque oceanográfico ARC-Quindío de la Armada de la República de Colombia. Los núcleos de sedimento fueron recuperados de las estaciones Titumate, Punta Arenas del Sur y Bahía Colombia (Figura 1). La estación Titumate se ubica en el costado noroccidental del golfo a $10.8 \mathrm{~km}$ mar adentro de la población de Titumate $\left(8^{\circ} 22^{\prime} 58,2^{\prime \prime} \mathrm{N} ; 7^{\circ} 01^{\prime} 43,14^{\prime \prime} \mathrm{W}\right)$ en el área de influencia de los ríos Atrato, Acandí, Tolo, Negro y Titumate, así como del aporte de sedimentos pelágicos, provenientes de organismos calcáreos y de una estrecha franja de bajos arrecifales de la costa occidental desde Sapzurro hasta Titumate (Thomas et al. 2007a). La profundidad del sitio de muestreo fue de 46,7 m. La estación Punta Arenas del Sur se ubica al noreste del golfo en la plataforma costera del municipio de Necoclí (8³0'2,22" N; 7654'28,14" W). En este sector los sedimentos corresponden fundamentalmente a la fracción granulométrica limo-arenosa y la profundidad alcanzó $34 \mathrm{~m}$. La estación Bahía Colombia se ubica en la plataforma costera sur del municipio de Turbo ( $7^{\circ} 59^{\prime} 45,54^{\prime \prime} \mathrm{N}$; $\left.76^{\circ} 45^{\prime} 23,82^{\prime \prime} \mathrm{W}\right)$, en la zona de influencia directa de las descargas de los ríos León, Currulao y Guadualito. Los sedimentos son predominantemente arcillas y la profundidad alcanzó $16 \mathrm{~m}$.

Los núcleos de sedimentos fueron extraídos con un nucleador de gravedad (gravity corer), $2 \frac{1}{2}$ " de diámetro y una capacidad de recuperación máxima de $5 \mathrm{~m}$. Al nucleador de gravedad se le introdujo un tubo de PVC del mismo diámetro, en el cual se recuperó el sedimento. Una vez que se extrajo el núcleo de sedimento, se selló herméticamente el tubo en los extremos y se rotuló con varias flechas dirigidas hacia el techo de la secuencia.
Los núcleos de sedimentos se mantuvieron en refrigeración y en posición vertical durante su transporte hasta el laboratorio del grupo GAIA (Grupo de Investigación en Gestión y Modelación Ambiental, Universidad de Antioquia) en la ciudad de Medellín, donde fueron conservados a $3{ }^{\circ} \mathrm{C}$.

Los tres núcleos recuperados se fragmentaron longitudinalmente en dos partes iguales y se describieron macroscópicamente. Para establecer la edad de los núcleos, fueron enviadas muestras de sedimentos con fragmentos de restos vegetales al Centro de investigaciones ambientales de la Universidad de Glasgow donde se realizaron tres dataciones con radiocarbono (Accelerator Mass Spectrometry; AMS C14), en el techo, centro y base de cada núcleo. El modelo de edad y edades calibradas fueron obtenidos mediante el programa Oxcal 4.0 (Bronk-Ramsey 2000) y posteriormente las edades indicadas fueron calculadas en años Antes del Presente (A.P). El modelo de edad radiocarbono fue calibrado por el Centro de investigaciones ambientales de la Universidad de Glasgow, de acuerdo a las edades de la Era Común o Después de Cristo (E.C) y a las edades antes de la Era Común o Antes de Cristo (A.C). Posteriormente las edades fueron calculadas en años Antes del Presente (A.P) y mostraron una correlación $\left(\mathrm{r}^{2}\right)$ alta con la profundidad o longitud de cada núcleo (Figura 2).

Determinación de materia orgánica y carbonato de calcio en los núcleos: Se realizó la determinación del contenido de materia orgánica y $\mathrm{CaCO}_{3}$ cada $5 \mathrm{~cm}$ a lo largo del núcleo. La materia orgánica se cuantificó mediante el método colorimétrico (Schumacher 2002, García \& Ballesteros 2005). La exactitud del método se evaluó con el material de referencia certificado (PACS-2 Consejo Nacional de Ciencia e Investigación de Canadá) y la recuperación alcanzó 108,6\%. La precisión del método se estimó mediante un sextuplicado de una misma muestra y se expresó como el coeficiente de variación $(0,4 \%)$. Para el análisis de materia orgánica se utilizaron $0,2 \mathrm{~g}$ de sedimentos liofilizados por muestra y se hicieron lecturas por triplicado en el espectrofotómetro.

La concentración de $\mathrm{CaCO}_{3}$ se determinó mediante un Calcímetro de Bernard. El método se basa en la reacción del ácido clorhídrico $(\mathrm{HCl})$ con el carbonato 


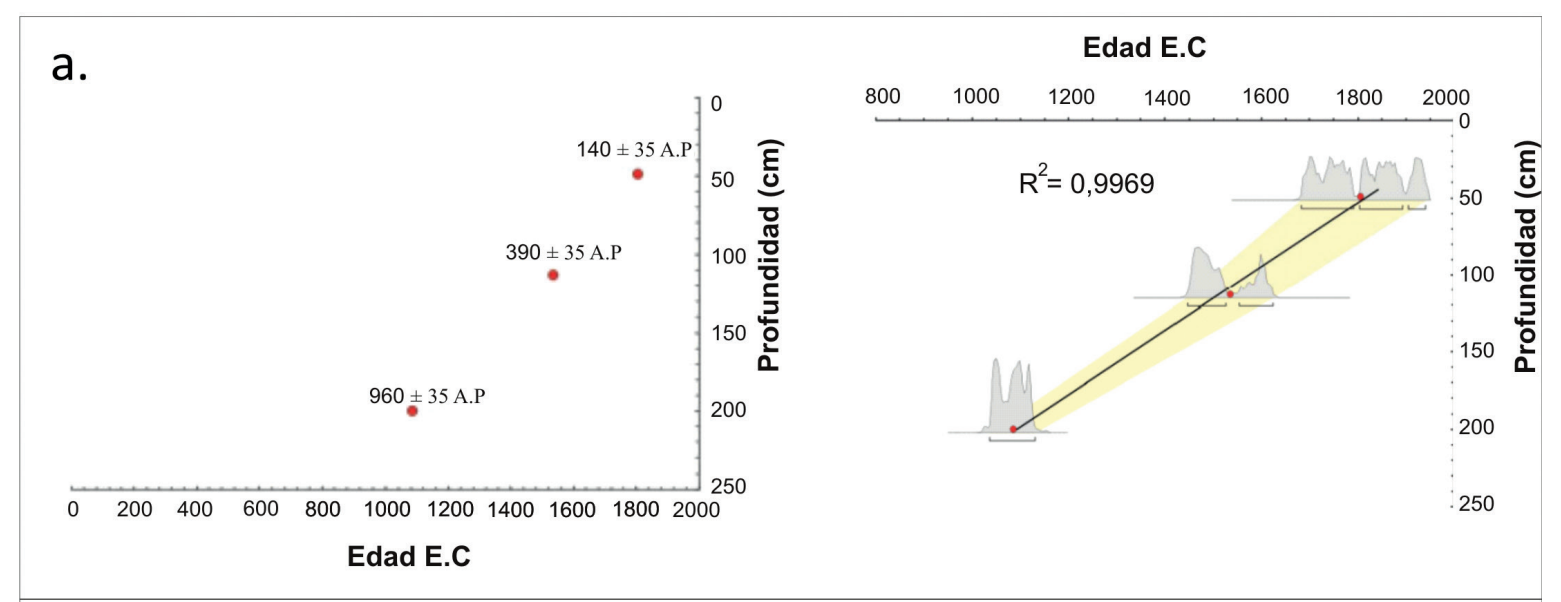

b.

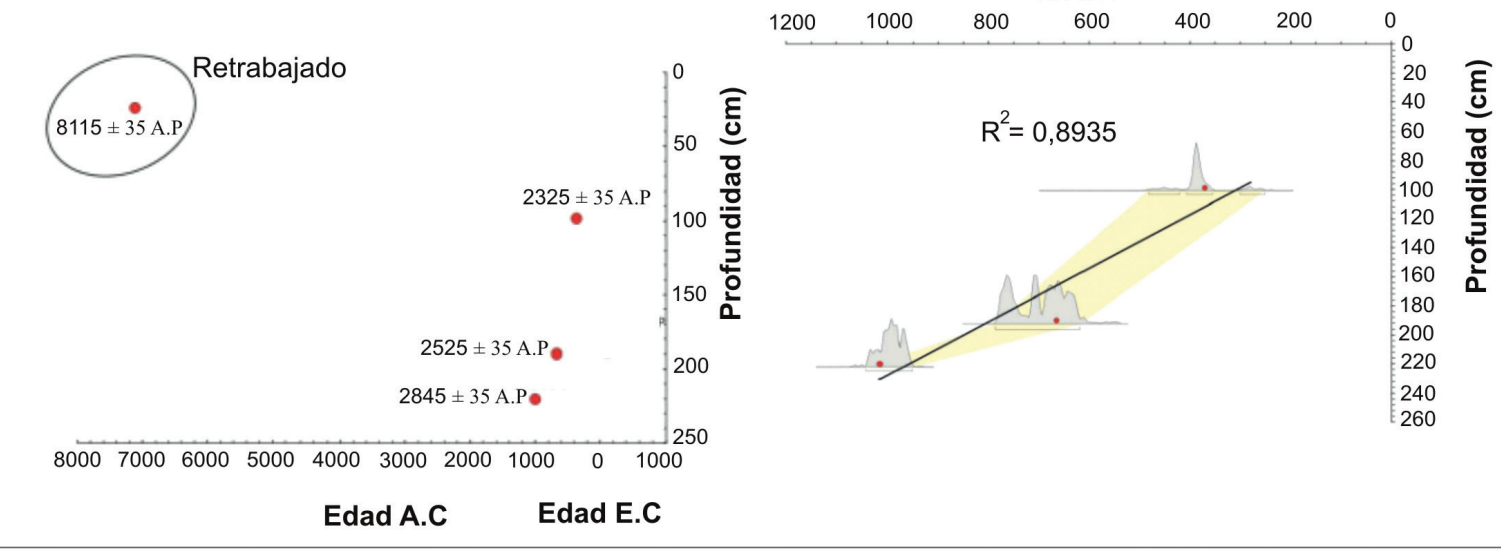

C.

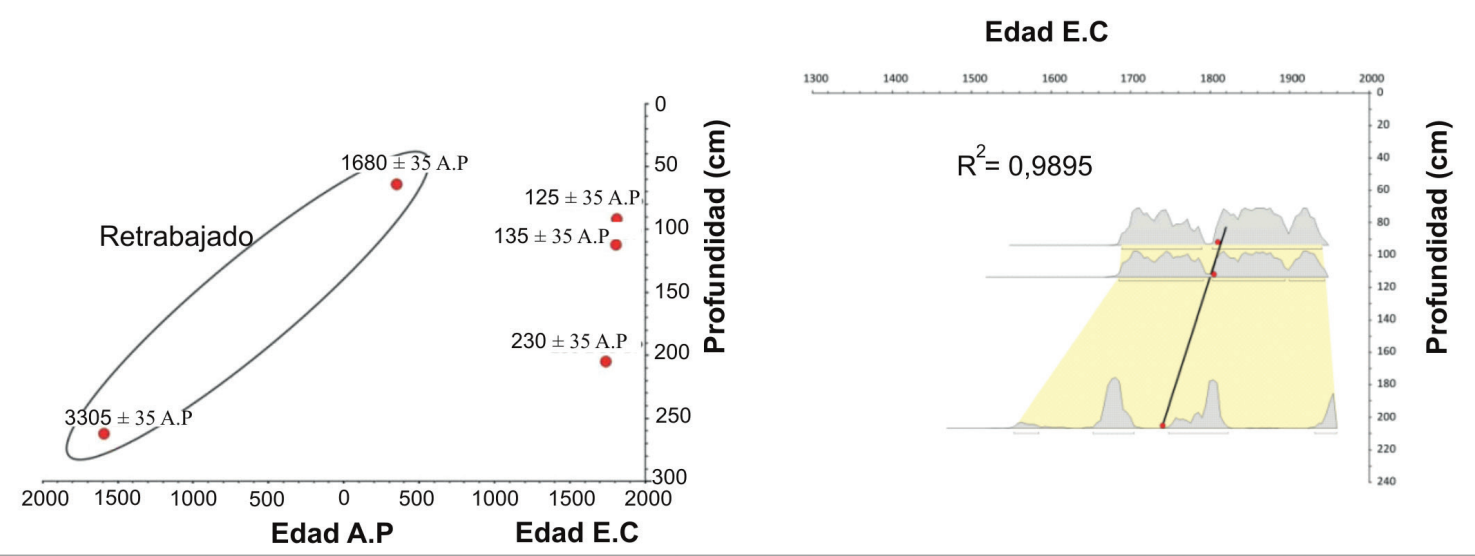

Fig. 2. Modelo de edad en los núcleos de sedimentos del golfo de Urabá. a. Edades radiocarbono del núcleo Punta Arenas $\left(\mathrm{r}^{2}=0.8935, \mathrm{~F}_{(1,1)}=5.13, \mathrm{p}=0.08\right) ; \mathrm{b}$. Edades radiocarbono del núcleo Titumate $\left(\mathrm{r}^{2}=0.9969, \mathrm{~F}_{(1,1)}=5.13\right.$, $\mathrm{p}=0.26) ; \mathbf{c}$. Edades radiocarbono del núcleo Bahía Colombia $\left(\mathrm{r}^{2}=0.9895, \mathrm{~F}_{(1,1)}=154.75, \mathrm{p}=0.05\right)$.

cálcico $\left(\mathrm{CaCO}_{3}\right)$ y con desprendimiento de anhídrido carbónico $\left(\mathrm{CO}_{2}\right)$, que desplaza un volumen de líquido indicador (solución hipersalina). Para el análisis se emplearon $0.2 \mathrm{~g}$ de sedimento seco por muestra y se hicieron dos repeticiones. Con el fin de lograr mayor confiabilidad del método, el calcímetro fue calibrado a temperatura ambiente con diferentes pesos de $\mathrm{CaCO}_{3}$ y se obtuvo alta correlación $\left(\mathrm{r}^{2}=0.998, \mathrm{~F}_{(1,18)}\right.$ $=9891.25, \mathrm{p}=0.00)$, entre los porcentajes de $\mathrm{CaCO}_{3}$ y el volumen desplazado en el calcímetro (Figura 3). 


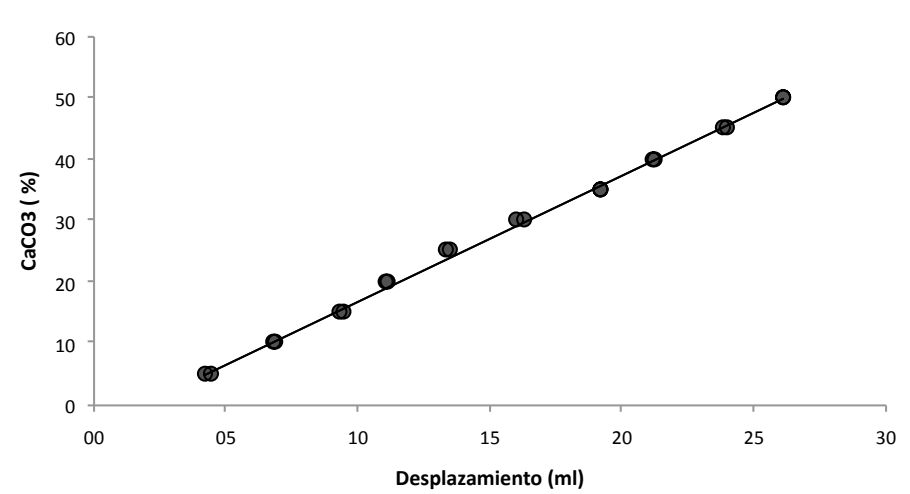

Fig. 3. Correlación entre el carbonato de calcio y el volumen desplazado en el calcímetro de Bernard. La alta correlación en la calibración del calcímetro demuestra la confiabilidad del método para hallar porcentajes de carbonato de calcio en los núcleos de sedimento $\left(\mathrm{r}^{2}=0.998, \mathrm{~F}_{(1,18)}=9891.25, \mathrm{p}=0.00\right)$.

Recuperación de los micromoluscos: De uno de los testigos del núcleo se tomaron dos centímetros de sedimento cada cinco centímetros a lo largo del núcleo, equivalente a 25-50 g aproximadamente de peso húmedo por muestra (Figura 4). Para separar los micromoluscos, se aplicó inicialmente agua y se emplearon pinceles de punta suave para disgregar los sedimentos. Luego, se separó el sedimento por tamizado de 250 y $500 \mu \mathrm{m}$ y el material retenido en cada tamiz se agregó a una solución de hipoclorito al 20\% entre 24 y 48 horas, según el contenido de materia orgánica. Normalmente se emplea peróxido de hidrógeno para disgregar los sedimentos y eliminar la materia orgánica, permitiendo separar los organismos calcáreos como los micromoluscos. Debido a la fragilidad de algunas conchas de micromoluscos, se comprobó que con una solución de hipoclorito de uso doméstico al 20\% es suficiente para lavar las muestras y evitar el deterioro y blanqueamiento de las conchas. Posteriormente, se lavó el material con abundante agua para eliminar la solución de hipoclorito, se filtró y se secó a $35^{\circ} \mathrm{C}$ durante un periodo inferior a 24 horas y se almacenó en recipientes plásticos pequeños. En total, se procesaron 45 muestras del núcleo Titumate, 41 de Punta Arenas y 53 de Bahía Colombia.

Las especies o morfotipos de micromoluscos fueron contadas en su totalidad en cada muestra y se fijaron en placas micropaleontológicas impregnadas con goma de tragacanto. Posteriormente, se observaron
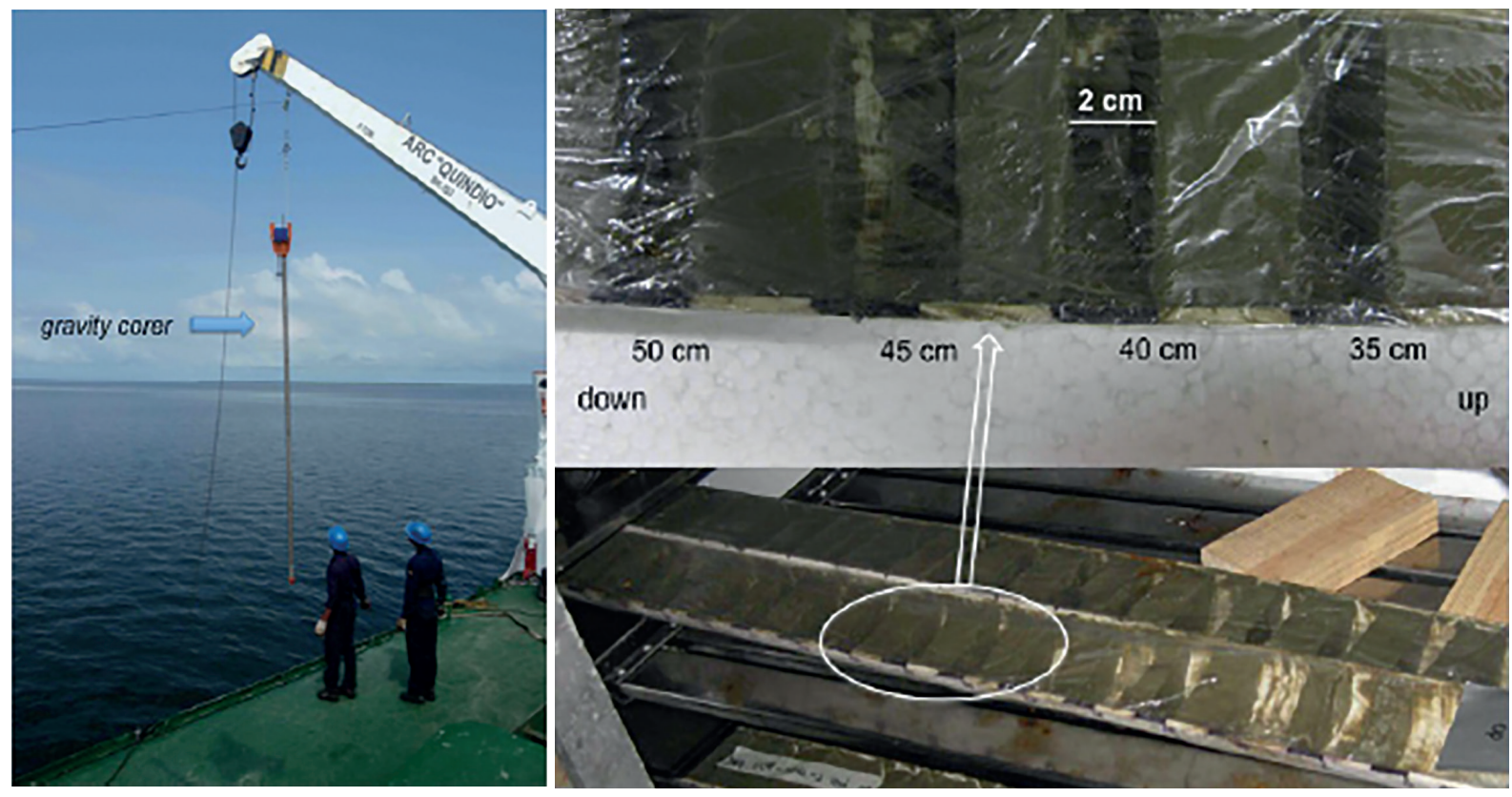

Fig. 4. Extracción de núcleos de sedimento en el golfo de Urabá: a. Uso del nucleador de gravedad para la extracción de los núcleos de sedimento y $\mathbf{b}$. Extracción de muestras de sedimento de $2 \mathrm{~cm}$ cada $5 \mathrm{~cm}$ desde el techo (up) a la base de cada núcleo (down) para determinar las concentraciones de carbonato de calcio, materia orgánica y riqueza y abundancia de micromoluscos. 
al microestereoscopio para su determinación y cuantificación. La identificación de las especies de micromoluscos se basó en trabajos reportados (Warmke \& Abbott 1961, Morris 1963, García-Cubas 1969, Díaz \& Puyana 1994, García-Valencia \& Díaz 2000, Yidi \& Sarmiento 2011).
Tratamiento de la información: Para relacionar las especies de micromoluscos más abundantes con la materia orgánica y el carbonato de calcio $\left(\mathrm{CaCO}_{3}\right)$ se utilizó el software $\mathrm{C}_{2}$, versión 1.5 (paleoecological analysis: Juggins 2007) que permitió realizar varios perfiles en una misma gráfica.

Tabla 1. Especies y abundancia de micromoluscos en los núcleos de sedimentos del golfo de Urabá.

\begin{tabular}{|c|c|c|c|c|c|c|c|}
\hline Micromoluscos & $\begin{array}{l}\text { Núcleo } \\
\text { Titumate }\end{array}$ & $\begin{array}{c}\text { Núcleo } \\
\text { Punta Arenas }\end{array}$ & $\begin{array}{c}\text { Núcleo } \\
\text { Bahía Colombia }\end{array}$ & Micromoluscos & $\begin{array}{l}\text { Núcleo } \\
\text { Titumate }\end{array}$ & $\begin{array}{c}\text { Núcleo } \\
\text { Punta Arenas }\end{array}$ & $\begin{array}{c}\text { Núcleo } \\
\text { Bahía Colombia }\end{array}$ \\
\hline Abra aequalis & 370 & 39 & 0 & Laevidentalium callipeplum & 43 & 10 & 4 \\
\hline Acteocina sp. & 60 & 43 & 15 & Lioglyphostoma aguadillanum & 3 & 0 & 0 \\
\hline Alvania colombiana & 1361 & 161 & 1 & Myrtea prystiphora & 4 & 19 & 3 \\
\hline Anachis obesa & 67 & 38 & 2 & Nannodiella vespuciana & 0 & 0 & 1 \\
\hline Atlanta peronii & 55 & 5 & 0 & Neritina sp. & 97 & 11 & 0 \\
\hline Bacteridium bermudense & 13 & 2 & 0 & Nucula dalmasi & 161 & 11 & 0 \\
\hline Bactrocythara asarca & 1 & 0 & 0 & Nuculana sp. & 45 & 3 & 13 \\
\hline Bankia sp1 & 0 & 0 & 1 & Nuculoida 1 & 48 & 60 & 1 \\
\hline Bankia sp2 & 2 & 0 & 0 & Odostomia cf. canaliculata & 30 & 0 & 0 \\
\hline Barbatia sp. & 4 & 0 & 0 & Odostomia cf. laevigata & 55 & 11 & 1 \\
\hline Bivalvia 1 & 41 & 45 & 0 & Odostomia sp. & 4 & 0 & 0 \\
\hline Bivalvia 2 & 91 & 17 & 0 & Odostomia sp3 & 12 & 0 & 0 \\
\hline Bivalvia 3 & 51 & 0 & 0 & Olivella $\mathrm{sp1}$ & 205 & 68 & 38 \\
\hline Caecum imbricatum & 40 & 0 & 0 & Ostrea sp. & 2 & 0 & 0 \\
\hline Calliostoma sp. & 25 & 1 & 0 & Parvilucina clenchi & 96 & 18 & 0 \\
\hline Cerodrillia sp. & 46 & 3 & 0 & Parvilucina multilineata & 2 & 0 & 15 \\
\hline Cleodora sp. & 3 & 1 & 0 & Pectinidae 1 & 5 & 0 & 0 \\
\hline Corbula contracta & 6 & 0 & 8 & Periploma sp. & 3 & 0 & 0 \\
\hline Corbula operculata & 88 & 3 & 21 & Petaloconchus erectus & 2 & 0 & 0 \\
\hline Crasinella martinicensis & 30 & 0 & 0 & Petaloconchus sp. & 2 & 46 & 0 \\
\hline Crenella divaricata & 30 & 0 & 0 & Pinnidae 1 & 0 & 6 & 0 \\
\hline Creseis acicula & 2133 & 849 & 24 & Polinices sp. & 68 & 0 & 3 \\
\hline Cyclostremiscus beaui & 147 & 5 & 0 & polyschides tetrodon & 5 & 0 & 14 \\
\hline Cyclostremiscus sp1 & 7 & 0 & 0 & Pyramidella crenulata & 52 & 3 & 1 \\
\hline Cyclostremiscus sp2 & 8 & 0 & 0 & Retusa sulfata & 31 & 1 & 0 \\
\hline Cylicbnella bidentata & 0 & 0 & 5 & Retusidae 1 & 32 & 32 & 6 \\
\hline Daphnella stegeri & 43 & 4 & 0 & Rimosodaphnella morra & 12 & 0 & 0 \\
\hline Decipifus sixaolus & 2 & 0 & 0 & Rissoina striosa & 197 & 22 & 0 \\
\hline Dentalium cf. laqueatum & 4 & 0 & 6 & Semele proficua & 100 & 58 & 1 \\
\hline Diacavolinia limbata & 44 & 0 & 2 & Strigilla $\mathrm{cf}$. producta & 55 & 38 & 0 \\
\hline Diplodonta sp. & 77 & 2 & 0 & Styliola subula & 1 & 0 & 0 \\
\hline Dosinia concentrica & 5567 & 390 & 2 & Teinostoma lerema & 1 & 0 & 0 \\
\hline Epitonium sp. & 1 & 6 & 0 & Teinostoma parvicallum & 4 & 0 & 0 \\
\hline Epyscinia inornata & 1 & 0 & 0 & Tellina sp. & 262 & 58 & 3 \\
\hline Eulima bifasciata & 50 & 15 & 0 & Tivela mactroides & 17 & 8 & 0 \\
\hline Finella dubia & 2774 & 192 & 1 & Trigoniocardia antillarum & 65 & 1 & 0 \\
\hline Gastropoda 1 & 197 & 62 & 0 & Triphora sp. & 40 & 3 & 0 \\
\hline Gastropoda 2 & 56 & 11 & 0 & Truncatella scalaris & 2 & 0 & 0 \\
\hline Gastropoda 3 & 151 & 17 & 0 & Turbonilla elegans & 7 & 0 & 0 \\
\hline Gastropoda 4 & 10 & 1 & 0 & Turbonilla pusilla & 81 & 40 & 14 \\
\hline Gemma gemma & 272 & 11 & 1 & Turbonilla sp1 & 8 & 3 & 1 \\
\hline Graptacme sp. & 27 & 48 & 0 & Turbonilla sp2 & 2 & 4 & 0 \\
\hline Haplococblias moolenbeeki & 157 & 23 & 1 & Turbonilla sp3 & 24 & 0 & 0 \\
\hline Haplococblias sp. & 7 & 0 & 0 & Verticordia ornata & 1 & 0 & 0 \\
\hline Haplococblias swifti & 2 & 00 & 0 & Vitrinella filifera & 120 & 14 & 0 \\
\hline \multirow{4}{*}{$\begin{array}{l}\text { Hyalocylus strata } \\
\text { Kurtziella serga }\end{array}$} & 8 & 1 & 0 & Vitrinellidae 1 & 331 & 54 & 0 \\
\hline & 22 & 24 & 4 & Vitrinellidae 2 & 290 & 17 & 0 \\
\hline & & & & Yoldia crosbyana & 63 & 21 & 1 \\
\hline & & Total & & & 16841 & 2659 & 214 \\
\hline
\end{tabular}


El análisis paleoambiental se realizó con las especies de micromoluscos marinos más abundantes en los núcleos: Semele proficua, Dosinia concentrica, Finella dubia, Alvania colombiana, Vitrinellidae 1, Olivella sp1, Turbonilla pusilla, Creseis acicula, Graptacme sp. y Polyschides tetrodon. De igual modo, se comparó con la riqueza y abundancia absoluta de todas las especies de micromoluscos encontradas en los núcleos de sedimento. Los índices de diversidad se calcularon por medio del software Biodiversity pro.

\section{Resultados}

Micromoluscos en los núcleos de sedimentos: En los tres núcleos de sedimentos se determinaron 102 morfotipos de micromoluscos, dentro de los cuales se identificaron 34 especies de micromoluscos de la clase Bivalvia, 64 de la clase Gastropoda y 4 de la clase Scaphopoda. En total se encontraron 19714 especímenes con tamaños entre 250 y $500 \mu \mathrm{m}$.

En el núcleo Titumate se identificaron 91 especies representadas por 16841 especímenes (Tabla 1). En el núcleo Punta Arenas se encontraron 57 especies y 2659 especímenes (Tabla 1). Por su parte, en el núcleo de Bahía Colombia se encontraron 32 especies y 214 especímenes. En este núcleo se encontró la menor abundancia de micromoluscos (Tabla 1).

Los índices de diversidad de micromoluscos en los núcleos de sedimento muestran mayor diversidad en el núcleo Bahía Colombia, seguido por Punta Arenas y el núcleo Titumate. De igual modo, la equidad de Pielou fue mayor a diversidades más altas (Tabla 2).

Tabla 2. Índices de diversidad de micromoluscos en los núcleos de sedimento del golfo de Urabá.

\begin{tabular}{|c|c|c|c|}
\hline & Е્ّ & 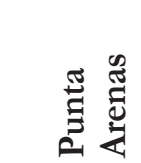 & ن \\
\hline$(\mathrm{H})$ & 1,13 & 1,207 & 1,238 \\
\hline & 0,577 & 0,687 & 0,823 \\
\hline (D) & 0,162 & 0,138 & 0,077 \\
\hline
\end{tabular}

Los resultados de diversidad de micromoluscos y sus componentes no reflejan claramente las diferencias en las condiciones ecológicas entre las tres estaciones consideradas en el estudio. Debido a su carácter marino, en el núcleo Titumate se esperaría encontrar una diversidad significativamente mayor que en el núcleo Bahía Colombia, con condiciones estuarinas.

En contraste al índice de diversidad, la curva de acumulación de especies muestra mayor diversidad de micromoluscos en el núcleo de Titumate, seguido del núcleo Punta Arenas y finalmente se observa una baja diversidad de especies en el núcleo Bahía Colombia (Figura 5).

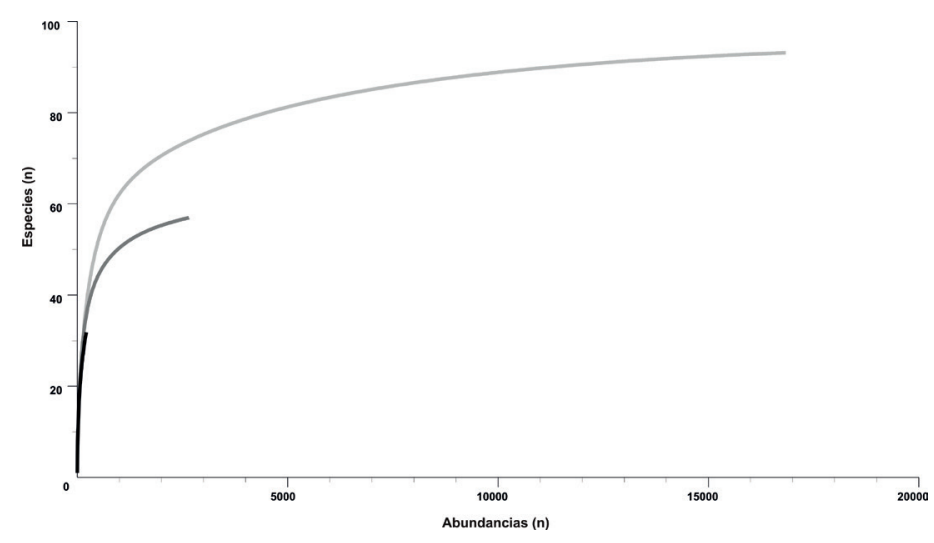

Fig. 5. Curva de acumulación de las especies de micromoluscos en los núcleos de sedimentos del golfo de Urabá. Se muestra la cantidad de especies encontradas en cada núcleo con respecto a la abundancia absoluta, la curva más baja pertenece al núcleo Bahía Colombia (-), la del medio a Punta Arenas (-) y la más alta al núcleo Titumate (-).

Las especies más representativas por su abundancia en los núcleos de sedimento (Figura 6) muestran un predominio de aguas marinas cálidas y salinidades altas. El hábitat y distribución de las especies (Díaz \& Puyana 1994) se describen a continuación:

Semele proficua: Común en fondos de arena mixta a gruesa y de cascajo, incluso vegetados con Thalassia, entre 1 y $55 \mathrm{~m}$ de profundidad. Su distribución abarca 


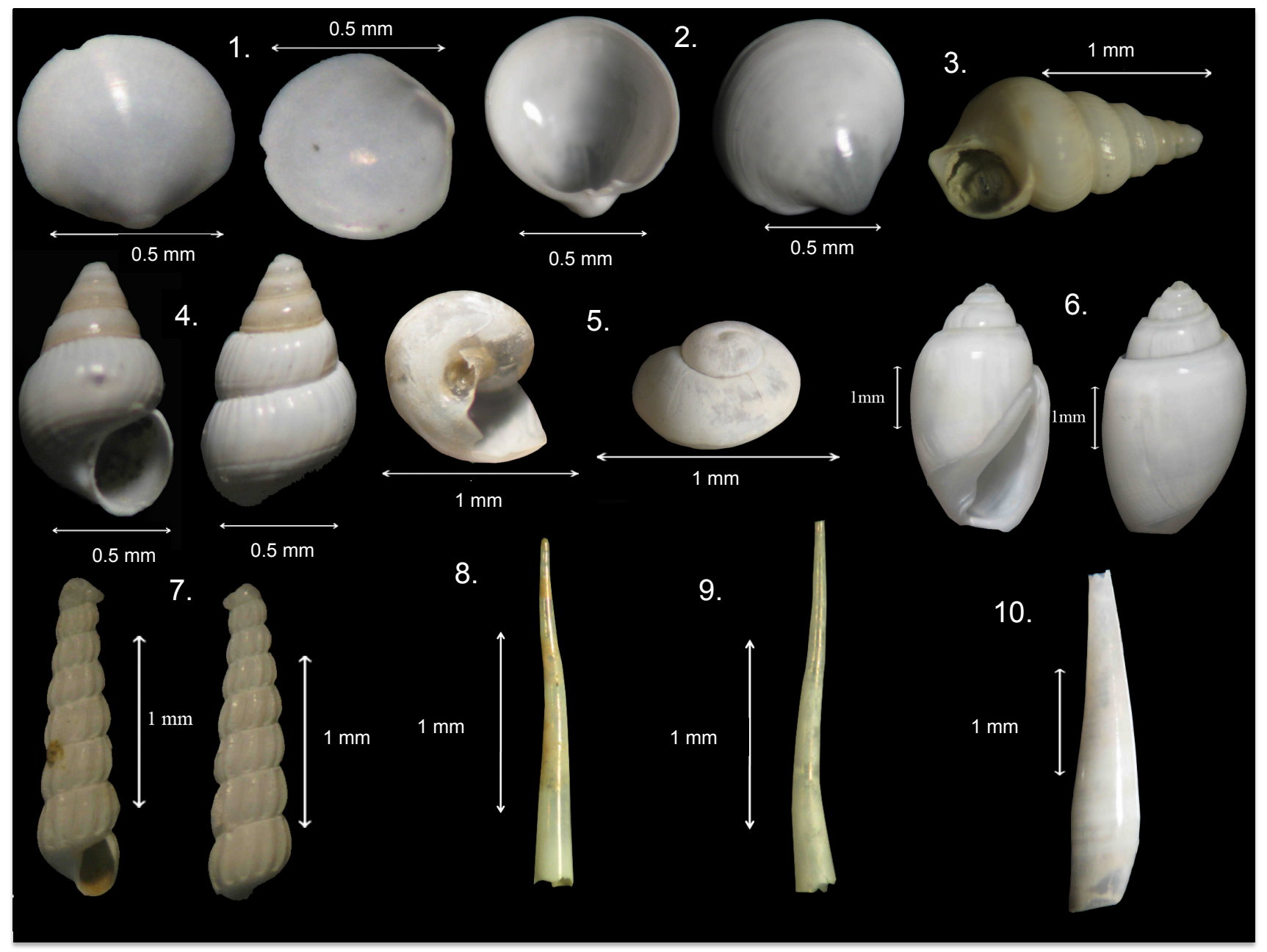

Fig. 6. Especies de micromoluscos abundantes en los núcleos de sedimentos del golfo de Urabá. 1. Semele proficua; 2. Dosinia concentrica; 3. Finella dubia; 4. Alvania colombiana; 5. Vitrinellidae 1; 6. Olivella sp1; 7. Turbonilla pusilla; 8. Creseis acicula; 9. Graptacme sp.; 10. Polyschides tetrodon.

el Atlántico occidental, desde Carolina del Norte hasta el norte de Argentina, en el Caribe colombiano se encuentra actualmente desde el golfo de Urabá hasta la Guajira y las Islas de San Andrés.

Dosinia concentrica: Relativamente común en arena fina y mixta, en la que se entierra unos $8 \mathrm{~cm}$, a profundidades entre 10 y $80 \mathrm{~m}$. Se distribuye en el Mar Caribe y la costa continental de Suramérica, desde las Antillas Mayores hasta el sur de Brasil. En el Caribe colombiano, se encuentra desde el golfo de Urabá hasta el Cabo de la Vela.

Finella dubia: Muy común sobre algas hasta $70 \mathrm{~m}$ de profundidad. Se encuentra en el Atlántico occidental, entre Carolina del Norte y el sur de Brasil.
Alvania colombiana: Habita en sedimentos finos entre 50 y $160 \mathrm{~m}$ de profundidad. Se observa en el Mar Caribe y en Caribe colombiano se tienen registros en el Magdalena y aguas oceánicas hasta 221m.

Vitrinellidae 1: Las especies de esta familia viven comúnmente en fondos arenosos hasta $80 \mathrm{~m}$ de profundidad y bajo rocas. Se encuentran en el Atlántico occidental.

Olivella sp1: Común en fondos areno-fangosos en aguas someras a moderadamente profundas. Se distribuye comunmente en el sur del mar Caribe.

Turbonilla pusilla: Común en fondos de arena $\mathrm{y}$ arena fangosa en aguas relativamente someras. 
Se distribuye en el Atlántico occidental, entre Carolina del Norte y Brasil.

Creseis acicula: Especie fitofaga, epipelagica y de aguas cálidas, temperatura entre $10-27,9^{\circ} \mathrm{C}$ y salinidad entre 35,5-36,7 ups. En la Laguna de Mandapan (India) esta especie vive entre $26-33{ }^{\circ} \mathrm{C}$ y salinidad de $25-45$ UPS (Marine species: Identification Portal). Hábitat: Pelágica, abundante en todo los mares tropicales. Distribución: Mares tropicales y subtropicales.

Graptacme sp.: Las dos especies reportadas para el Caribe colombiano (G. eboreum y G. semistriolatum) habitan en fondos de arena fina y calcárea hasta $120 \mathrm{~m}$ de profundidad (Díaz \& Puyana 1994). Distribución: Atlántico occidental, Caribe colombiano.

Polyschides tetrodon: Habita en fondos de arena a poca profundidad. Distribución: La Florida, Bahamas y Colombia.

Análisis paleoambiental: El núcleo Titumate con longitud de $260 \mathrm{~cm}$ contiene los sedimentos más antiguos del golfo y una edad radiocarbono de cerca de 2800 años A.P, el núcleo Punta Arenas tiene una longitud de $250 \mathrm{~cm}$ y una edad de aproximadamente 960 años A.P . Entre tanto, el núcleo Bahía Colombia es mucho más reciente con cerca de 235 años A.P y fue el de mayor longitud $(265 \mathrm{~cm})$. Litológicamente los sedimentos son homogéneos a lo largo de los núcleos con una dominancia de limos y limos arenosos.

En el núcleo Titumate, la riqueza total de especies, la abundancia absosulta de todos los micromoluscos hallados, así como las especies Alvania colombiana, Creseis acicula, Dosinia concentrica y Finella dubia mostraron bajas abundancias en los últimos 2000 años. Entre tanto, hacia los años 2845 y 2300 años A.P se evidencia una notable abundancia y riqueza de especies que coinciden con mayores concentraciones de carbonato de calcio (Figura 7).

En el núcleo Punta Arenas, el carbonato de calcio se mantuvo alrededor del 4\%, a excepción de los 180 $\mathrm{cm}$ de longitud del núcleo, donde se incrementa y aparentemente se relaciona con un leve aumento de las abundancias de micromoluscos (Figura 8). Este comportamiento podría estar asociado a cambios regionales de la salinidad y/o temperatura.

En el núcleo Bahía Colombia las bajas abundancias no permiten establecer una tendencia clara de la distribución de las especies a través del núcleo. En consecuencia, no se evidencia alguna relación entre
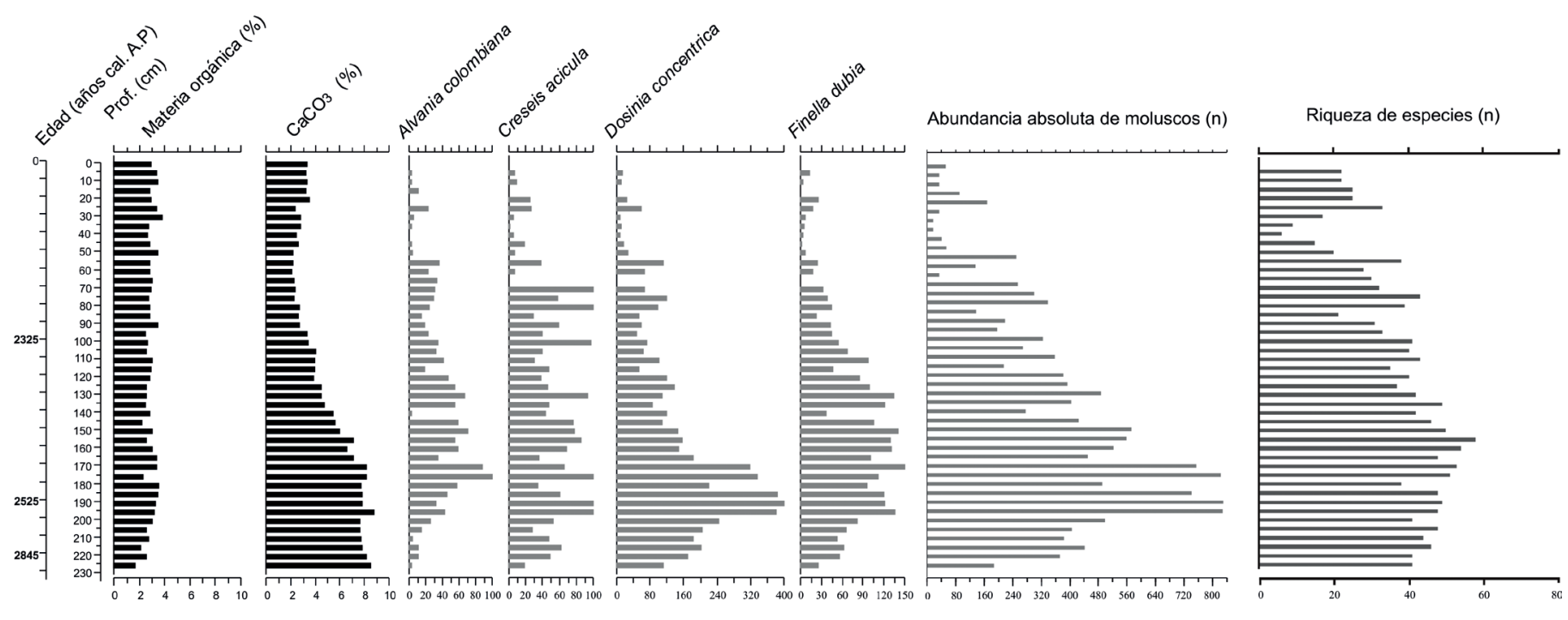

Fig. 7. Distribución y abundancia de especies de micromoluscos, materia orgánica y $\mathrm{CaCO}_{3}$ en el Holoceno tardío del núcleo Titumate. El primer eje vertical señala las edades radiocarbono y el segundo la profundidad o longitud del núcleo, las concentraciones de materia orgánica y carbonato de calcio $\left(\mathrm{CaCO}_{3}\right)$ se expresan en porcentaje y las especies, abundancia y riqueza de micromoluscos se expresan en abundancias absolutas. 


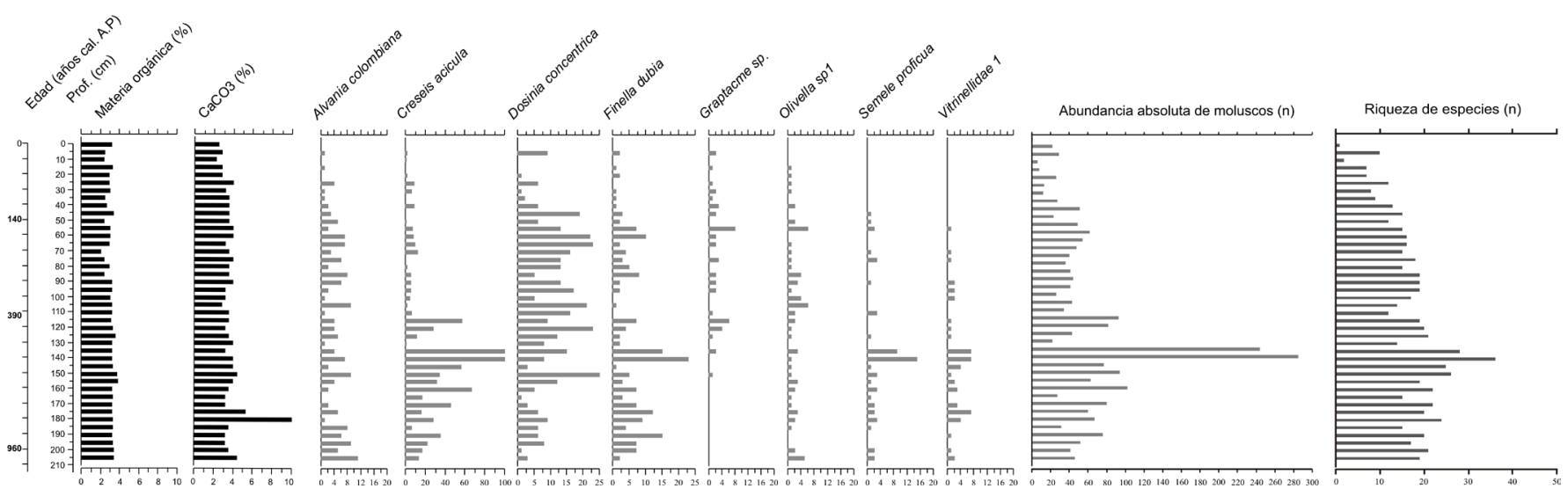

Fig. 8. Distribución y abundancia de especies de micromoluscos, materia orgánica y $\mathrm{CaCO}_{3}$ en el Holoceno tardío del núcleo Punta Arenas. El primer eje vertical señala las edades radiocarbono y el segundo la profundidad o longitud del núcleo, las concentraciones de materia orgánica y carbonato de calcio $\left(\mathrm{CaCO}_{3}\right)$ se expresan en porcentaje y las especies, abundancia y riqueza de micromoluscos se expresan en abundancias absolutas.

las abundancias de las especies y la concentración del carbonato de calcio como indicador de las condiciones de salinidad predominantes a través de la edad del núcleo. Sin embargo, en el núcleo Bahía Colombia se evidenció una mayor abundancia y riqueza entre 135-125 años A.P y en los recientes 100 años se reduce considerablemente los micromoluscos (Figura 9). La reducción de los micromoluscos podría estar asociada a las altas tasas de sedimentación que actualmente se observan en el sur de Bahía Colombia (Thomás et al. 2007b).
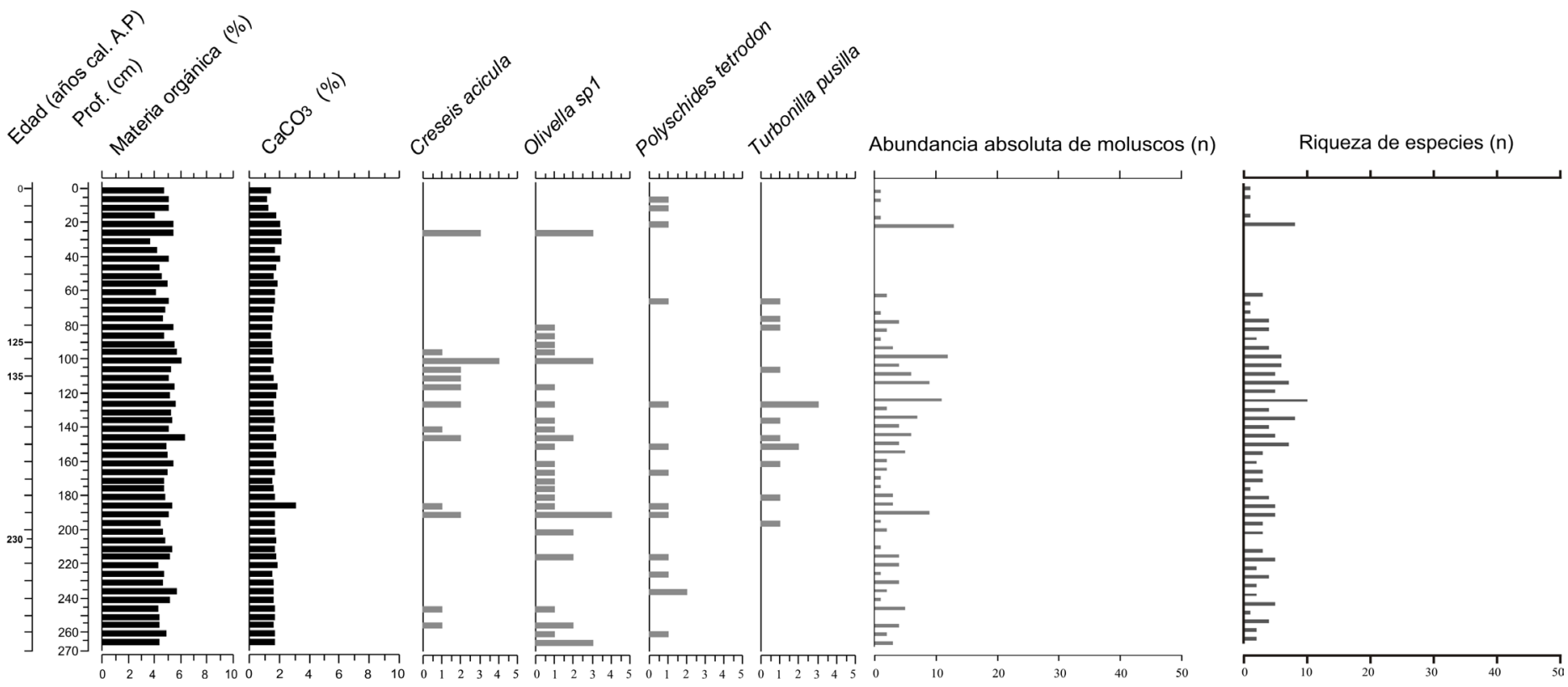

Fig. 9. Distribución y abundancia de especies de micromoluscos, materia orgánica y $\mathrm{CaCO}_{3}$ en el Holoceno tardío del núcleo Bahía Colombia. El primer eje vertical señala las edades radiocarbono y el segundo la profundidad o longitud del núcleo, las concentraciones de materia orgánica y carbonato de calcio $\left(\mathrm{CaCO}_{3}\right)$ se expresan en porcentaje y las especies, abundancia y riqueza de micromoluscos se expresan en abundancias absolutas. 


\section{Discusión}

El núcleo Titumate es el más antiguo y demuestra una relación directa entre el carbonato de calcio y los micromoluscos. El incremento del carbonato de calcio desde los $100 \mathrm{~cm}$ hasta la base del núcleo, coincidió con el aumento de la riqueza y abundancia de micromoluscos. Esta relación indica condiciones de aguas marinas en este sector del golfo hace aproximadamente entre 2800 a 2325 años A.P. y a partir de 2325 años A.P aproximadamente hasta el presente. Los aportes de agua dulce pudieron aumentar y en el período más reciente también aumentaron las cargas de materia orgánica. Este resultado se sustenta a través de las menores concentraciones de carbonato de calcio y las más bajas abundancias de los micromoluscos marinos en la parte superior del núcleo. En general, las concentraciones de carbonato de calcio, la abundancia y riqueza de micromoluscos reflejan cambios ambientales en el Holoceno tardió y una mayor influencia de aguas estuarinas en los recientes 2000 años; donde inició el declive de los micromoluscos recientes y posiblemente de otras especies marinas.

En el núcleo Punta Arenas se identificaron cambios en la riqueza y abundancia de micromoluscos que podrían estar asociados a recientes eventos climáticos. Si se tiene en cuenta que El Optimo Medieval (PCM), ocurrió entre 1064-764 años A.P y que la Pequeña Edad de Hielo se extendió entre 614-164 A.P; es posible que estos pequeños cambios de temperatura hayan afectado la riqueza y abundancia de micromoluscos en el golfo de Urabá, tal como se observa en los años 960 a 230 A.P del núcleo Punta Arenas que coincide con la manifestación de los anteriores eventos climáticos.

La edad más reciente del núcleo Bahía Colombia está relacionada con una acumulación mayor de sedimentos en este sector. De acuerdo con Thomás et al. (2007b), cerca del 61\% de la carga de sólidos de los ríos costeros y del río Atrato se deposita en Bahía Colombia a una tasa entre 1 y $8 \mathrm{~cm} /$ año. Estos valores podrían estar evidenciando una crisis erosiva actual asociada a las actividades humanas (minería, extracción de madera, dragado de sedimentos y expansión urbana en las zonas costeras) en la cuenca del Río Atrato y demás tributarios del golfo (Thomas et al. 2007b).
Las concentraciones de materia orgánica fueron superiores en el núcleo Bahía Colombia con un promedio de 4,9\%. La similaridad de los contenidos de materia orgánica en la secuencia del núcleo Bahía Colombia indica que no se han presentado cambios importantes durante los últimos 235 años A.P (aproximadamente) en este sector. Roldán (2008) encontró que entre más finos son los sedimentos del golfo, mayores son los contenidos de materia orgánica. En la parte media del golfo, (delimitada por Triganá, Boca Tarena, Turbo y Necocli) y la zona central de Bahía Colombia, que es el sitio de mayor acumulación de sedimentos (24\%), se presentan mayores concentraciones de materia orgánica. Entre tanto, las acumulaciones de arenas presentan los contenidos más bajos de materia orgánica en el golfo $(2 \%)$. Esta configuración de los sedimentos estudiada por Roldán (2008), se relacionó igualmente con las concentraciones de materia orgánica en el reciente estudio. Teniendo en cuenta que el fondo del golfo de Urabá está constituido en un $80 \%$ por lodos terrígenos que son aportados por los principales ríos y que estos lodos se desplazan en suspensión y se depositan por decantación (Chevillot et al. 1993), la mayor distribución de los sedimentos finos al interior del golfo se debe a que la mayoría de este material terrígeno es depositado en el sur y centro del golfo y debido al efecto de las corrientes y los vientos, las aguas dulces son confinadas hacia el interior y la costa oriental del golfo.

Según las condiciones actuales del golfo es de esperarse que las concentraciones de materia orgánica sean superiores en los sedimentos de Bahía Colombia, debido a su ubicación en el sur, en un área de influencia directa de los principales tributarios de agua dulce.

Por su parte, la concentración de carbonato de calcio fue mayor en el núcleo Titumate, donde a partir de los $100 \mathrm{~cm}$ de profundidad se incrementó hasta la base del núcleo. Entre tanto, en el núcleo Punta Arenas se encontraron valores medios con una leve tendencia ascendente hacia la base y en el núcleo Bahía Colombia los valores fueron inferiores a los encontrados en los demás núcleos. Según GarcíaValencia (2007) esta misma tendencia se detectó en los sedimentos superficiales con la calcita en el sector de Bahía Colombia (0,5\%), en Punta Arenas $(1,5-2 \%)$ y en Titumate $(6 \%)$. El mayor contenido de 
carbonato de calcio en el núcleo Titumate corrobora la gran influencia marina que hubo en este sector, especialmente desde los $100 \mathrm{~cm}$ hasta la base del núcleo; es decir, hace más de 2000 años.

Según Alvarez (2008), los contenidos de carbonato de calcio en los sedimentos del golfo de Urabá son bajos con respecto a otras zonas del Caribe colombiano. Los sedimentos en donde se detectó carbonato de calcio se encuentran en el sector noroccidental y frente a las bocas de los ríos Atrato, León y Suriquillo. El mayor contenido (9.4\%) se encuentra en la zona noroccidental, donde se encuentran los arrecifes coralinos del sector (Alvarez 2008).

En general, la materia orgánica en los núcleos del golfo de Urabá presentó un promedio de 4\%, siendo relativamente inferior hacia el costado noroccidental donde litológicamente el fondo es limo-arenoso. La concentración de carbonato de calcio es inferior en los sedimentos holocénicos del núcleo localizado en el sur del golfo y se incrementa en dirección norte, especialmente hacia el noroeste. Esta configuración se observa igualmente en los sedimentos recientes.

Finalmente, debe considerarse el no uso de índices de diversidad en estudios paleoambientales, debido a que una muestra con pocas especies y alta equidad como ocurrió en el núcleo Bahía Colombia puede reportar un valor igual a otra con alta riqueza pero a la vez gran dominancia como en el caso del núcleo Titumate (Ramírez 2005). Por tal razón, el índice de diversidad no es confiable y debe analizarse la diversidad en términos de abundancia absoluta y riqueza de especies (número de especies; Melic 1993).

\section{Conclusión}

En total se encontraron 102 morfotipos de micromoluscos en los núcleos. La malacofauna del techo de los núcleos presentó una menor riqueza de especies con respecto a la base de los mismos. Esto podría significar que las condiciones ambientales actuales son menos favorables para el desarrollo de los micromoluscos.

El cambio de las condiciones ambientales holocénicas en el golfo de Urabá se podría explicar a partir de la relación entre la malacofauna y la concentración de carbonato de calcio en el núcleo de la estación Titumate. En este núcleo, se observó una misma tendencia entre el aumento del carbonato de calcio y las abundancias de las especies. La abundancia de las especies de micromoluscos y el incremento del carbonato de calcio en el núcleo Titumate, indican que entre 2845 hasta 1386 años AP, las condiciones ambientales del Holoceno tardío en este sector del golfo fueron dominadas por aguas marinas.

En síntesis, la abundancia y riqueza de micromoluscos dieron respuesta a los cambios ambientales del Holoceno tardío y permitieron definir dos ambientes contrastantes en el golfo de Urabá durante los últimos 2800 años; un ambiente más antiguo dominado por aguas marinas y un ambiente de mezcla más reciente dominado por aguas estuarinas.

\section{Agradecimientos}

Los autores desean expresarsus sinceros agradecimientos al personal del proyecto Erosión costera en Antioquia: Dinámica sedimentaria del golfo de Urabá. Erosión -depositación durante los últimos 10.000 años, realizado por las Universidades EAFIT, Nacional de Medellín y Antioquia y cofinanciado por COLCIENCIAS (código RC525-2008), sin ellos no hubiese sido posible la realización de este trabajo de investigación.

A todas las personas del grupo GAIA y la Corporación Académica Ambiental de la Universidad de Antioquia, profesores y amigos que de una u otra manera contribuyeron en la presente investigación.

De igual forma, queremos agradecer y rendir memoria a Luis Fernando Vásquez Bedoya, uno de los autores del presente artículo, excelente persona y profesional, donde quiera que se encuentre más allá de la muerte pedimos por su eterno descanso.

Finalmente agradecemos al programa de sostenibilidad de la Universidad de Antioquia y a los revisores de este manuscrito que con sus valiosos comentarios contribuyeron en su adecuada presentación.

\section{Conflicto de intereses}

Los autores declaramos que no existe conflicto de intereses. 


\section{Referencias}

Álvarez A (2008) Estudio del transporte de sedimentos superficiales en el piso marino del golfo de Urabá. Tesis de Maestría, Universidad Nacional de Colombia, Medellín

Bronk-Ramsey C (2009) Bayesian analysis of radiocarbon dates. Radiocarbon 51(1):337-360

Chevillot P, Molina M, Giraldo L, Molina C (1993) Estudio geológico e hidrológico del golfo de Urabá. Boletín Cientifico CIOH 14:79-89

De Francesco C (2002) Significado paleobiológico y paleoambiental de las concentraciones holocenas de Heleobia (Gastropoda) presentes en el sudeste de la Provincia de Buenos Aires. Tesis doctoral. Universidad Nacional de Mar del Plata. Facultad de Ciencias Exactas y Naturales. Argentina

Díaz JM, Puyana M (1994) Moluscos del Caribe Colombiano. Un catálogo ilustrado. Colciencias -Fundación Natura-Invemar

Farinati EA (1994) Micromoluscos (Gastrópoda y Bivalvia) del Holoceno del área de Bahía Blanca, Argentina. Ameghiniana 31(4):303-315

Farinati EA, Spagnuolo JO, Aliotta S (2006) Bioerosión en micromoluscos holocenos del estuario de Bahía Blanca, Argentina. Ameghiniana 43(1):45-54

García-Cubas A (1969) Ecología y distribución de los micromoluscos de la Laguna de Tamiahua, Veracruz, México. Universidad Nacional Autónoma de México. Boletín del Instituto de Geología 91:1-81

Garcia J, Ballesteros M (2005) Evaluación de parámetros de calidad para la determinación de carbono orgánico en suelos. Revista Colombiana de Quimica 34(2):201-209

García-Valencia C, Díaz JM (2000) Moluscos y su taxocenosis en los fondos someros del sector sur de la plataforma continental del Caribe colombiano. Boletín de Investigaciones Marinas y Costeras 29:73-80

García-Valencia C (2007) Atlas del golfo de Urabá: una mirada al Caribe de Antioquia y Chocó. Instituto de Investigaciones Marinas y Costeras (INVEMAR) y Gobernación de Antioquia. Serie de Publicaciones Especiales de Invemar $N^{\circ} 12$. Santa Marta, Colombia

García JM, Correa JD (2006) Macroinvertebrados y peces asociados a las raíces sumergidas del mangle rojo (Rhizophora mangle) en las bahías Turbo y el Uno, golfo de Urabá (Caribe colombiano). Trabajo de grado, Corporación Académica Ambiental, Universidad de Antioquia, Colombia

Gaviria DM (2006) Macroinvertebrados asociados a macroalgas marinas de litorales rocosos del golfo de Urabá, Caribe Colombiano. Trabajo de grado, Corporación Académica Ambiental, Universidad de Antioquia, Colombia
IGAC (2008) Atlas Básico de Colombia. Instituto Geográfico Agustín Codazzi. Imprenta Nacional de Colombia, Bogotá.

Juggins S (2007) Software forecological and palaeoecological data analysis and visualisation. User guide (versión 1.5)

Lozano LH (1998) Caracterización y diagnóstico integral de la zona costera que comprende la bahía Colombia desde el río Turbo hasta Matuntugo. Escuela Naval Almirante Padilla, Facultad de Oceanografía Física, Cartagena de Indias, Colombia

Manjarrés G (1978) Observaciones e inventario preliminar de los moluscos en el golfo de Urabá citado por Werding \& Manjarres (1978) En: Informe sobre las estructuras litorales y la flora y fauna marina en el Nor-Oeste del golfo de Urabá. Instituto de Investigaciones Marinas. Santa Marta, Colombia

Marine species (2012) Identification Portal. http:/ / speciesidentification.org/species.php?species_group=pelagic_ molluscs\&id $=264 \&$ menuentry $=$ soorten. Consultado en Abril de 2012

Melic A (1993) Biodiversidad y riqueza biológica: Paradojas y problemas. Zapateri: Revista aragonesa de entomología 3:97-103

Mesa O, Poveda G, Carvajal LF (1997) Introducción al clima de Colombia. Universidad Nacional de Colombia, Medellin

Morris P (1963) A field guide to the shells of our Atlantic and Gulf Coast. The Riberside Press. Cambrige, Massachusetts

Ospina JB (2008) Epifauna móvil asociada a una pradera de Thalassia testudinum en la Bahía Triganá, golfo de Urabá, Colombia. Trabajo de grado. Corporación Académica Ambiental, Universidad de Antioquia, Colombia

Palacio J (1988) Ecología de la fauna asociada a las raíces del mangle (Rhizophora mangle) en la bahía de Marirrío, Urabá. Trabajo de investigación. Facultad de Biología, Universidad de Antioquia, Colombia

Palacio-Baena J, Ospina-Hoyos JB, Estrada-Urrea EA, Villa-Zuluaga N, Vargas-Ochoa AF, Garcia-Padilla JM, Correa-Rendon JD, Delgado-Madrid JC, Gaviria-Soto DM (2014) Biodiversidad marina del golfo de Urabá. Imprenta Universidad EAFIT, Medellín, Colombia

Philander SG, Gu D, Halpern D, Lambert G, Lau N, Pacanowski RC (1996) Why the ITCZ is mostly north of the Equator? Journal of climate 9:2958-2972

Ramírez A (2005) Ecología Aplicada: Diseño y Análisis Estadístico. Fundación Universidad de Bogotá Jorge Tadeo lozano, Colombia

Roldán P (2008) Modelamiento del patrón de circulación de la bahía Colombia, golfo de Urabá. Implicaciones para el transporte de sedimentos. Tesis maestría. Posgrado de Recursos Hidraúlicos de la Universidad Nacional, Medellín, Colombia 
Seilacher A, Hagadorn JW (2010) Early Molluscan Evolution: Evidence from the Trace Fossil Record. Palaios 25(9):565-575

Schumacher B (2002) Methods for the determination of total organic carbon (TOC) in soils and sediments. Environmental Protection Agency (EPA), United States

Thomas YF, Valencia CG, Cesaraccio M, Rojas X (2007a) El paisaje en el golfo. En: García-Valencia C (ed) Atlas del golfo de Urabá: una mirada al Caribe de Antioquia y Chocó. Instituto de Investigaciones Marinas y Costeras-Invemar- y Gobernación de Antioquia. Serie de Publicaciones Especiales de Invemar $\mathrm{N}^{\mathrm{o}}$ 12. Santa Marta, Colombia

Thomas Y, Cesaraccio M, García C, Ménanteau L (2007b) Contribución de la hidrografía histórica al estudio de la cinemática de los fondos marinos: evolución del golfo de Urabá, Colombia. Boletín científico CIOH 25:110-119

Valencia C, Diaz JM (2000) Moluscos y su taxocenosis en los fondos someros del sector sur de la plataforma continental del Caribe colombiano. Boletin de Investigaciones Marinas y Costeras 29(1):73-80

Vargas AF (2008) Estructura de la pradera de Thalassia testudinum (bank ex konig, 1805) y la macroepifauna asociada en la Bahía Sapzurro, golfo de Urabá, Colombia. Tesis de grado. Corporación Académica Ambiental, Universidad de Antioquia, Colombia.

¿Responden los micromoluscos a los cambios ambientales durante el Holoceno tardío en el sur del mar Caribe colombiano?

Resumen. En el sector austral del mar Caribe se desconocen los cambios ambientales holocénicos y sus implicaciones en la composición de la micro-malacofauna marina. Se realizó una expedición oceanográfica a bordo del buque ARC-Quindío de la Armada de la República de Colombia; para realizar perforaciones en tres sitios del golfo de Urabá, utilizando nucleador de gravedad en plataforma. Se estudió la composición taxonómica (materia orgánica y carbonato de calcio) y abundancia de micromoluscos; para relacionarlos con posibles cambios paleoambientales durante el holoceno tardío en el golfo. Se estableció que la alta riqueza y abundancia de los micromoluscos se da a mayor carbonato de calcio y menor materia orgánica. La abundancia y riqueza de micromoluscos dieron respuesta a cambios ambientales del Holoceno tardío. Se logró definir dos ambientes contrastantes en el golfo de Urabá durante los últimos 2800 años; un ambiente más antiguo dominado por aguas marinas y un ambiente de mezcla más reciente dominado por aguas estuarinas.

Palabras clave: Micromoluscos marinos; Holoceno tardío; golfo de Urabá; carbonato de calcio; materia orgánica.
Warmke G, Abbott T (1961) Caribbean Seashells. A guide to the Marine Mollusks of the Puerto Rico and other West Indian Islands, Bermuda and the Lower Florida Keys. Livingston Publishing Company, Wynnewood, Pennsylvania

Werding B, Manjarres G (1978) Informe sobre las estructuras litorales $y$ la flora $y$ fauna marina en el noroeste del golfo de Urabá. Instituto de Investigaciones Marinas de Punta Betín (INVEMAR), Fondo Colombiano de Investigaciones Científicas y Proyectos Especiales Francisco José de Caldas, Santa Marta, Colombia

Yidi E, Sarmiento V (2011) Colombian Seashells from the Caribbean sea. Editorial L'Informatore. Italia

Zamora BP, López A, Sierra-Correa PC (2008) Formulación de los lineamientos y estrategias de manejo integrado de la Unidad Ambiental Costera del Darién. INVEMAR, GOBERNACIÓN DE ANTIOQUIA, CORPOURABA, CODECHOCO. Santa Marta, Colombia.

¿Respondem os micro-moluscos às alteraçóes ambientais durante o Holoceno tardio no sul do mar Caribe colombiano?

Resumo. No sector austral do mar Caribe se desconhecem as alterações ambientais holocénicas e as suas implicações na composição da micro-malacofauna marinha. Realizouse uma expedição oceanográfica a bordo do navio ARCQuindío da Armada da República de Colômbia; para realizar perfurações em três sítios do golfo de Urabá, utilizando nucleador de gravidade em plataforma. Estudouse a composição taxonómica (matéria orgânica e carbonato de cálcio) e abundância de micro-moluscos; para relacionálos com possíveis alterações paleoambientais durante o holoceno tardio no golfo. Estabeleceu-se que a alta riqueza e abundância de micro-moluscos deram resposta a alterações ambientais do Holoceno tardio. Conseguiuse definir dois ambientes contrastantes no golfo de Urabá durante os últimos 2800 anos; um ambiente mais antigo dominado por águas marinhas e um ambiente de mistura mais recentemente dominado por águas estuarinas.

Palavras-chave: Micromoluscos marinhos; Holoceno tardio; golfo de Urabá; carbonato de cálcio; matéria orgânica. 